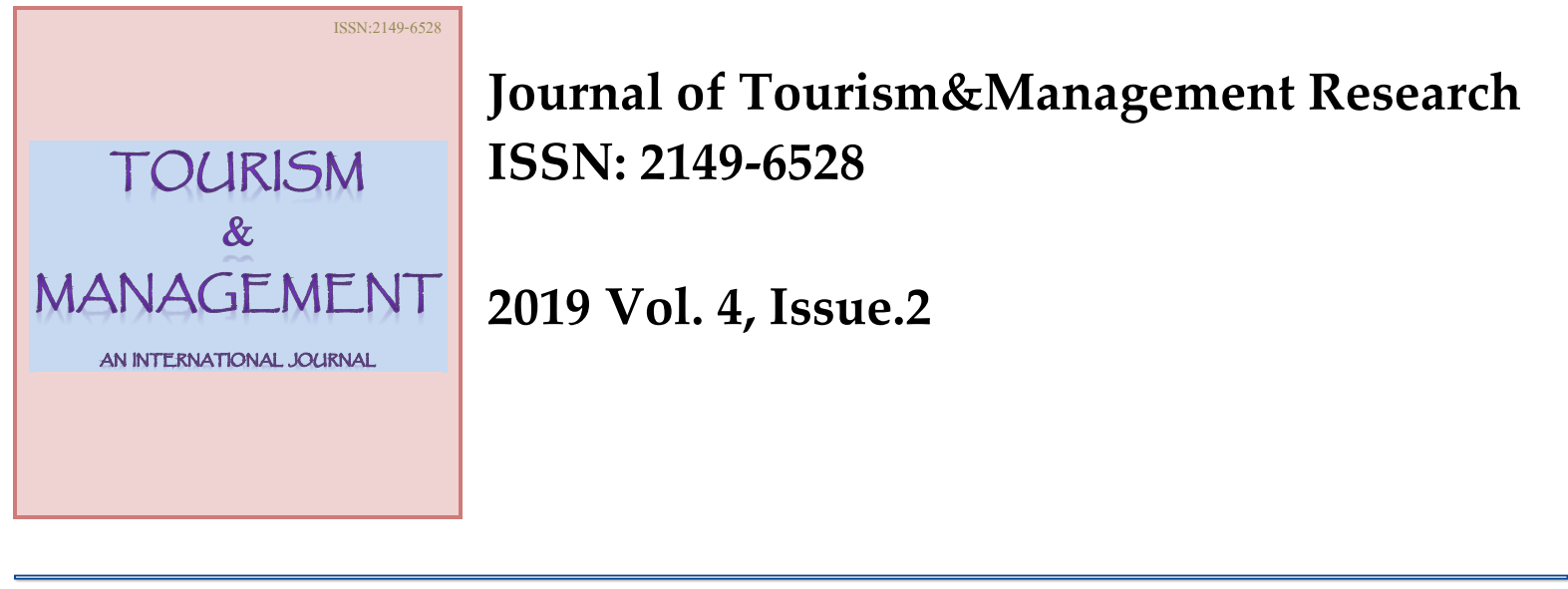

\title{
Tourist behavioral loyalty: a comparison of first-time and repeat tourist in the UNESCO World Heritage Site (WHS) in Malaysia
}

\begin{abstract}
The present study aims to investigate the structural relationships among food involvement, food knowledge, food experience, food image, destination image, overall satisfaction and behavioral loyalty across first-time and repeat tourist groups from the perspective of food tourism. The study also examines if differences exist in these variables across the two groups of tourists. The 'catch-as-catch-can' technique was used to sample international tourist in Melaka and George Town, Malaysia. A total of 1200 questionnaires were collected on-site and $75 \%$ of the total was randomly picked using SPSS, resulting in 868 responses analyzed. The two-step approach of structural equation modeling (SEM) was used to accomplish the study objectives. The $t$-test analysis demonstrated that repeat tourists expressed significantly higher food knowledge and behavioral loyalty than first-time tourists. The SEM results revealed that the structural model differed across first-time and repeat customers. This research contributes to the theoretical understanding of behavioral loyalty process across firsttime and repeat tourists in the World Heritage Site (WHS) of Malaysia from the food perspective.
\end{abstract}

Keywords: Past experience, Food behavior, Behavioral loyalty, Food image, Destination image

JEL classifications: D03; L83; M31.

Submitted:10/03/2019; Accepted:17/06/2019

Quee-Ling, Leong. Assistant Professor. (Corresponding Author). Faculty of Hospitality \& Tourism Management, UCSI University, KL Campus Lot 12734, Jalan Choo Lip Kung Taman Taynton View, 56000 Cheras, Kuala Lumpur, Malaysia. Tel: +603 91018880

Email: leongql@ucsiuniversity.edu.my

Shahrim Ab.Karim. Associate Professor. Faculty of Food Science \& Technology Universiti Putra Malaysia 43400, Serdang, Selangor, Malaysia. Tel: 603-97698409

Email: shahrim@upm.edu.my 


\section{Introduction}

Destination attractiveness is often associated to its capacity to fulfill tourists' essentials and anticipations. Combined with scenery, climate, accommodation, and ease of access, experiencing local foods is among the most important features when tourists evaluate a destination's attractiveness (Zakaria \& Aziz, 2018). Food consumption is not merely to feed one's physical needs but also an important experience to learn about a destination's culture and traditions. Cuisine of a place is in fact, innate in the destination's intangible heritage and the consumption experience is claimed to be a form of alternative tourism in many destinations as an attraction (Okumus et al., 2007). Food is a priceless attraction in destinations as it can primarily motivate tourists to embark on a food trip (Stanley and Stanley, 2015).

Due to the role food plays as part of tourists' travel motivation, Stanley and Stanley (2015) claimed that destinations without 'local food offer' would hardly survive. Consumers nowadays have substantial access to various types of information with just a click on the computer. Thus, tourists now do not only seek the in-trend of a destination but also want to personally experience new food and the meaning of food as they travel to unfamiliar places. Even tourists who are not keen on exotic food experience would want to enjoy food to fulfill their physiological needs (Sanchez-Canizares \& Lopez-Guzman, 2012).

In 2008, Melaka and George Town were officially declared as United Nations Educational, Scientific and Cultural Organization (UNESCO) World Heritage Site (WHS) (UNESCO, 2008). Being the settlement to various colonial powers in the past, Malacca and Penang are melting pots of the Portuguese, Dutch, British and Asians flavors (Khoo \& Badarulzaman, 2014b). The local fare has almost always been a charm in drawing tourists to visit the states (Khoo \& Badarulzaman, 2014a; 2014b). Although both Malacca and Penang have endured the influence of several similar colonial powers, due to geographical distance, the cuisines in the states demonstrate slight dissimilarities in certain food qualities resulting from regional influences (Khor, 2006).

In recent years, food tourism has been recognized as an emerging market in which it has become one of the most dynamic sectors within the tourism industry (UNWTO, 2017). Many countries are beginning to utilize their local food to attract the world to their doorstep (Stanley \& Stanley, 2015). Malaysia is also embarking on capitalizing its food offerings to attract tourist influx. Penang was nominated as world's top food destination in 2014 by Lonely Planet (Barton, 2014). The number of international tourist arrivals to Penang increased by 56.8\% (3.23 million) in that year from 2.06 million in 2013 (Tourism Malaysia, 2016). Meanwhile, the number of international tourist arrivals in Malacca remained relatively constant at approximately 1.8 million at the same period (ibid). Syllogizing this scenario based on the statistics, it is evident that there was a shift in tourists' behavior towards Penang, especially when the city was highlighted as the best haven for delectable cuisines by Lonely Planet (Barton, 2014). However, there was no significant changes in Malacca. It comes to show that gastronomy might have acted as a stimulus that has induced tourists' interest towards the destination which resulted in a significantly revived number of tourist arrivals to Penang in 2014.

Numerous academic research has been documented on the connection between food and tourism in Malaysia (e.g. Hendijani \& Boo, 2014; Leong et al., 2017; Omar \& Omar, 2018). The capital cities of both Malacca and Penang - Melaka and George Town - likewise, received much attention from academic scholars (e.g. Khoo \& Badarulzaman, 2014a; 2014b; Yousefi \& Marzuki, 2015; Hussin, 2018; Tan et al., 2019). Literature has shown a positive contribution of gastronomy as a unique tourism product in the past decades. However, there are still dearth of empirical evidences regarding the linkages between food preference, food image, destination image, satisfaction and behavioral loyalty in the WHS; despite Penang 
being nominated as world's top food destination by Lonely Planet. Therefore, the main interest of this study is to empirically determine the systematic differences in the proposed structural tourist behavioral loyalty model across first-time and repeat tourists in the WHS of Malaysia.

\section{Literature Review and Hypotheses Development \\ 2.1 Food Preference}

According to Almeida and Garrod (2017), tourists' food preference and choices may vary while vacationing. The variation that exists may form a range of perceptions towards a destination and ultimately different behavioral intentions. In this study, the term food preference is used to denote an individual's affection towards the food of a destination. The theoretical foundation used to underpin this term is derived from the recreational specialization theory. As per the explanations by past scholars, not all the tourists' fondness towards a product or activity is similar. Instead, it comprises a range of behavior formed by the varying degrees of affective, cognitive and behavioral components in individuals (Bryan, 1977). The affective, cognitive and behavioral components are mutually connected, and they reflect an individual's personal system towards an object or activity of interest (McIntyre \& Pigram, 1992). Following the work of the authors, the concept of involvement is used to reflect the affective component of food preference. The cognitive component is assessed using the knowledge concept and the concept of prior experience in relation to the food is used to reflect the behavioral component of tourists' food preference.

\subsection{Tourist's Food Involvement and Perceived Food Image}

Engel and Blackwell (1982) suggested that the degree of involvement in relation to consumers' behavior can be illustrated on a scale that covers from low to high levels towards a subject matter. Researchers (i.e. Belk, 1981; Mitchell, 1979) of consumer goods proposed that consumers under the low involvement cluster would generally portray the following characteristics: relatively passive in information search, usually do not compare product attributes, have low sensitivity to the differences among products under the same category, and do not have distinct fondness for a specific product. Meanwhile, consumers of the high involvement cluster would have the opposite attributes compared to above mentioned characteristics as they are more particular and sensitive towards the specific product of their preference. When traveling, tourists are usually surrounded by 'fresh' food encounters due to cultural and geographical differences. Thus, people would tend to have a higher level of interest or involvement in food related activities during trips, resulting in higher food consumption compared to normal days at home (Mitchell \& Hall, 2003). This in turn assists to enhance travel experience through senses (Kivela \& Crotts, 2006).

Food involvement concept was utilized by Guan (2012) to profile tourists based on their food preferences. The positive relationship between tourists' food involvement and tourists' perceived overall destination image was confirmed by Guan and Jones (2015) from the food tourism context. Therefore, it is plausible to hypothesize that tourists' food involvement has a direct influence on their perceived food image. In the same study, Guan and Jones (2015) also hypothesized that tourists' involvement of food in a destination would as well contribute to forming their perceptions on the destination. The relationship between food involvement and perceived destination image was rationalized based on the notion that food is culturally inherent within a destination; thus, the authors theorized that the overall perception of destination image would be more favorable when tourists are increasingly involved in the food activity domain within a destination (Guan \& Jones, 2015). Based on the relationship established by the authors, it is therefore rational to state that tourist's food involvement positively contributes to perceived food image and destination image. 
Hypothesis 1a: Tourists' food involvement has a positive effect on perceived food image. Hypothesis 1b: Tourists' food involvement has a positive effect on perceived destination image.

\subsection{Tourist's Food Knowledge and Perceived Food Image}

Knowledge or the amount of information sources upheld by individuals is a prevalent element that has influence on the person's perceptions toward a product or service and decisionmaking process (Jeong \& Holland, 2012; Kivela \& Crotts, 2006). Consumer knowledge is defined as the degree of familiarity that an individual has towards a product or service prior to engaging in external information search behavior (Rao \& Monroe, 1988). In the tourism context, knowledge about a destination's local food can be obtained through food consumption experience (Fields, 2002) or from other information sources such as electronic or printed media. Mak et al. (2012) regarded local food knowledge of a destination as a motivator for food tourists to partake food tourism activity. At the same time, it functions as a source of information to feed the curiosity of general tourists in forming part of their travel experience (Charters \& Ali-Knight, 2002). However, irrespective of the type of tourists (food tourist or general tourist), the ones who are more knowledgeable about a destination's local food would tend to be more satisfied with their food experiences and subsequently increases their food perceptions (Kivela \& Crotts, 2006).

Additionally, local food knowledge is claimed to be a factor that has effect on tourist's perceived destination attractiveness (Guan \& Jones, 2015). For example, an individual who has learned about the food culture of a destination of interest through various information sources would definitely have good overall mental images representation about the destination. Therefore, it is hypothesized that tourist's food knowledge has a direct influence on their perceived food image and destination image.

Hypothesis 2a: Tourists' food knowledge has a positive effect on perceived food image.

Hypothesis 2b: Tourists' food knowledge has a positive effect on perceived destination image.

\subsection{Tourists' Past Food Experience and Perceived Food Image}

In consumer behavior studies, prior experience has been noted as an essential element that influences the present or future behavior. The experience gained in the past may be the basis forming a set of beliefs which in turn influences one's perceptions at varying degrees, depending on the intensity of the past experience encountered (Reibstein et al., 1980). From the tourism perspective, past experience is a crucial element that forms the basis of perceptions or beliefs of a destination and tourists' behavior (Mak et al., 2012; Zhang et al., 2016).

Tourist's involvement, knowledge and past experience are three components that constantly underpin a tourist's personal preference system (Trauer, 2006). For instance, a tourist with higher level of food involvement in a destination would certainly have more past encounters related to local food, which in turn reinforces the individual's food knowledge. In view of past experiences strengthens knowledge (a cognitive response to the food eaten), it is believed that the tourist's mind would generate perceptions towards the food and the destination resulting from the cognition process (Schiffman \& Kanuk, 2009). Therefore, from the food tourism context, it can be anticipated that tourists with more intended recurring food experiences might reflect a higher personal preference towards the food of a destination and perceive it more favorably.

On-site food consumption experience is said to be of influence to the way a tourist experience a destination (Kivela \& Crotts, 2006). Past food experience may act as a predictor of tourists' future behavioral loyalty towards a destination (ibid). Additionally, in destination 
attractiveness studies (Cracolici \& Nijkamp, 2008; Hu \& Ritchie, 1993), quality of food experience is identified as a component that plays a role in influencing destination image in general. As such, it is believed that tourists' food experience has an effect on their perceived destination image. The following are the hypothesized relationships between food experience, perceived food image, and destination image:

Hypothesis 3a: Tourists' food experience has a positive effect on perceived food image.

Hypothesis 3b: Tourists' food experience has a positive effect on perceived destination image.

\subsection{Food and Destination Image}

Favorable images or attractiveness are important terms employed by tourism scholars to assess the performance of destinations from the tourists' angle (Buhalis, 2001; Ritchie \& Crouch, 2003). Past research on destination image or attractiveness are generally concentrated on examining the ability of the destination-related attributes to satisfy tourists (Eusébio \& Vieira, 2013; Reitsamer \& Brunner-Sperdin, 2015). Mayo and Jarvis (1981) intellectualized destination attractiveness as an individual's mental perceptions of a destination's ability and propensity to provide specific benefits to him/her. Reitsamer and Brunner-Sperdin (2015) suggested that since destination attractiveness is an integrated representation of a destination, a unified perception of a destination is a prerequisite of tourists' cognitive, affective and behavioral reaction's formation, which would subsequently impact their perception, behavior and destination choice (Henkel et al., 2006).

Food is a vital component reflecting a society's culture and identity. Through food sampling experiences, tourists get to immerse and engaged deeply within the society in a destination to understand the local culture. Food is a symbolic code of non-verbal communication of a community that functions as a communication channel within a society as well as an indirect repository of traditions signifying the cultural roots in within (Civitello, 2008). Though food consumption, tourists would tend to perceive a destination more positively through all the knowledge learned through the "food communication channel" (Hjalager \& Corigliano, 2000).

Among the pioneers, Gearing et al. (1974) contributed in the area of destination attractiveness studies by developing the measure of touristic attractiveness. By taking Turkey as the research setting, the authors generated 17 measurement items for evaluation of the touristic area. The items were categorized under five dimensions: (1) natural factors, (2) social factors, (3) historical factors, (4) recreational and shopping facilities, and (5) infrastructure, food and shelter. In this study, Gearing et al. (1974) claimed that 'natural beauty and climate' are the most crucial factors that determine the attractiveness of Turkey. Later, in another setting, Kivela and Crotts (2006) discovered food as the primary factor that has influence on Hong Kong's attractiveness from the context of touristic experience. Similarly, several other studies reported that food is becoming a prevalent factor that determine a destination attractiveness or general image (Andriotis et al., 2008; Reitsamer \& Brunner-Sperdin, 2015). Therefore, the following hypothesis on the relationship between food and destination is drawn as following:

Hypothesis 4: Tourists' perceived food image has a positive effect on perceived destination image.

\subsection{Destination Image and Satisfaction}

Satisfaction is a concept that is crucial in marketing literature. The concept has gained much attention from scholars of consumers' studies as satisfaction is viewed as the ultimate 
conditions desired by consumers. Oliver (2010) explained that satisfaction responses may occur at the end or in the interim of a consumer's processing activities and not necessarily only in situations where the consequences are observed instantaneously. With this nature of satisfaction, the concept allows quick satisfaction reactions on simple consumable products such as a chocolate bar, in addition to a summation of satisfaction judgments on products with very long consumption periods such as the satisfaction with a holiday trip or a university education (Oliver, 2010). In addition, the author connoted that an interim evaluation of satisfaction may emerge prior to an overall satisfaction reaction and the combination of interim and final judgments generates the perceived level of satisfaction received.

From the tourism standpoint, food may be viewed as a supporting product to a total tourism experience (Horng \& Tsai, 2012; Quan \& Wang, 2004). Rust and Oliver (2000) said that food consumption can be an exciting activity, especially when one is experiencing food that is outlandish to his/her own culture. Similarly, Chen and Huang (2016) suggested that the influence of food in inducing ecstatic touristic experience should not be taken lightly. The process of experiencing the novelty of food may induce excitement in individuals as it is human nature to be curious about something that is not routine (Rust \& Oliver, 2000). The perception gained through experiences is claimed by Chen and Tsai (2007) to have a positive impact on both satisfactions and consumer's behavioral intention such as revisit intention and positive word-of-mouth. Food and destination, being regarded as complementary elements that contribute to a tourist's overall travel experience, it is therefore postulated that:

\section{Hypothesis 5: Tourists' perceived food image has a positive effect on tourist's overall satisfaction.}

Hypothesis 6: Tourists' perceived destination image has a positive effect on tourist's overall satisfaction.

\subsection{Satisfaction and Behavioral Loyalty}

Tourists' loyalty is an asset of the utmost significance to any tourism destinations. Acknowledging the significance of loyalty in tourism, Campon et al. (2013) claimed that there are still many gray areas within the tourism sector as in how to retain tourists in the long-term. Customer loyalty has been described to a great extent by past scholars. On a general note, customer loyalty is interpreted as the behavior associated to customers' repeated consumption of a product or service due to a favorable affective attachment (Dick \& Basu, 1994; Petrick, 2004). From a more profound perspective, customer loyalty is determined using two distinct methods by marketing scholars (Jacoby \& Kyner, 1973; Yi, 1990). The first type explains customer loyalty from the perspective of customers' attitude or feelings in relation to a product or service. Meanwhile, the second type describes customer loyalty as a behavioral function of repeated consumption and positive communication.

Scholars found that tourists who return to a destination are those whom are satisfied with their past travel experiences. These tourists would also engage in positive word-of-mouth about the destination to people surrounding them (Chen \& Tsai, 2007; Han et al., 2018). Hui et al. (2007) observed that a tourist's recurring visitation to a destination and their loyalty towards the destination are in fact related to the inner satisfaction of the tourist's initial travel experience. The emotional satisfaction attained from the overall vacation experience would be a form of input that influences tourists' future revisit intentions to the same destination or country (Kozak \& Rimmington, 1999). Gallarza and Saura (2006) denoted that satisfaction is positively connected to loyalty in tourists' holiday experience. Similarly, Kim et al. (2011) also confirmed the effects of satisfaction on behavioral intention among food tourists in the U.S. Therefore, the association between travel satisfaction and destination loyalty is hypothesized as follows: 
Hypothesis 7: Tourists' overall satisfaction has a positive effect on tourists' behavioral loyalty.

\subsection{The Proposed Model}

Scholars believe that the tourism market consists of distinct subgroups with different needs and desires (McKercher et al., 2002; Mumuni \& Mansour, 2014; Swarbrooke \& Horner, 2007). The authors emphasized that it is crucial for destination marketers to understand the existence of specific groups within the tourists market in order to perform better in providing service that matches the target group's desired qualities. The differences between the distinct groups are deemed to have an effect on how a destination is perceived.

Several studies have demonstrated that the number of past visits to a destination has an influence on tourists' perceived destination image (Rodriguez Molina et al., 2013; San Martin et al., 2013). The scholars believed that familiarity with a destination may lead to place attachment, hence resulting in a more holistic and favorable psychological perceptions and connections to the destination. Therefore, this study also attempts to examine the moderation effect of past experience on the tourists' behavioral loyalty model. Figure 1 illustrates the proposed model of tourist's behavioral loyalty with hypotheses described formerly.

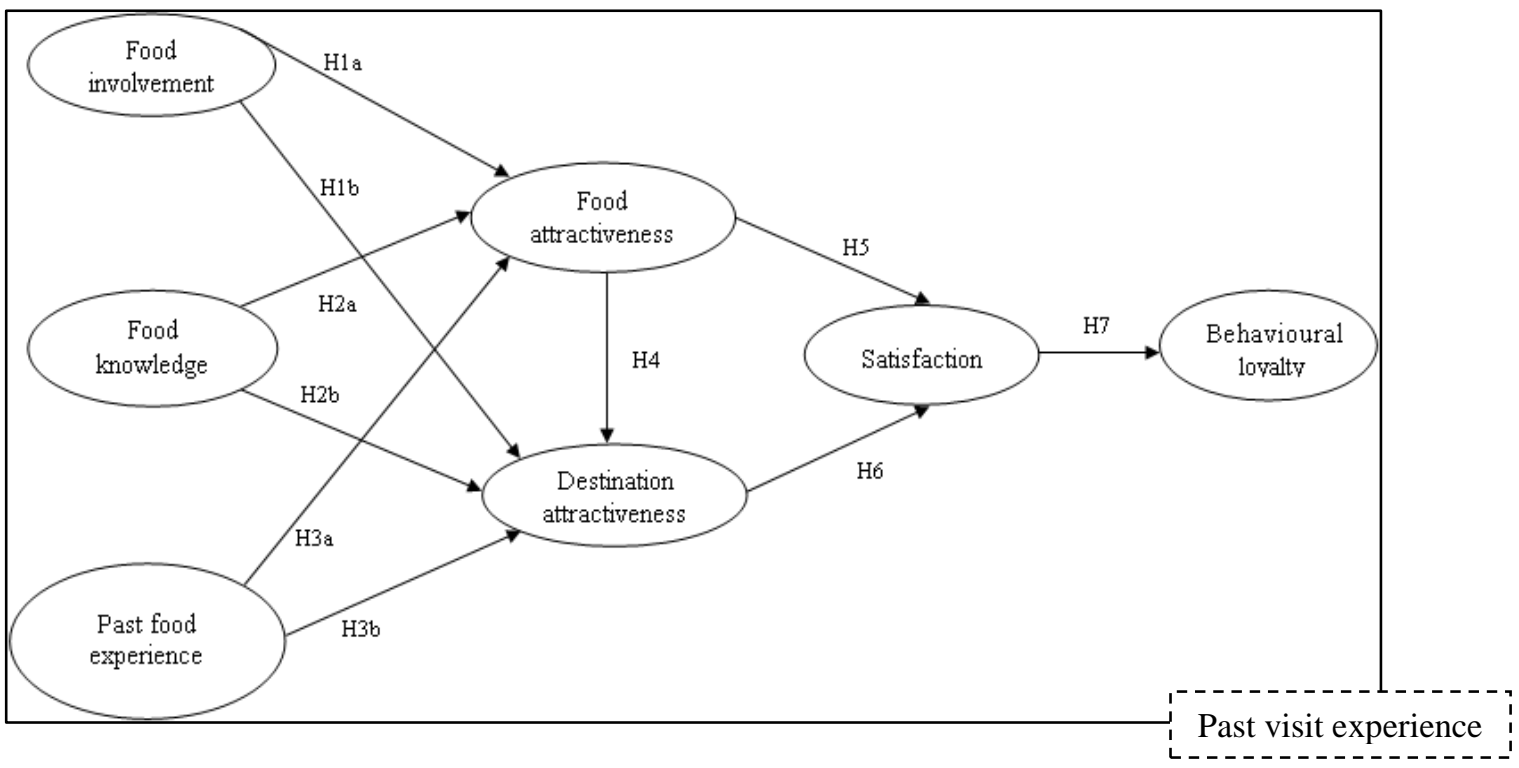

Figure 1: Proposed model of tourist's behavioral loyalty.

\section{Methodology}

Data was collected using a self-administered questionnaire in George Town and Melaka, Malaysia, which took place between January to February 2015. The targeted respondents were international tourists who were visiting the destination at the point of survey; a noncitizen or a non-permanent resident of Malaysia; a tourist who has stayed in the destination for at least 24 hours but less than one year; and a tourist who has tasted the local food in the destination prior to participating in the survey. Respondents who were couples or in a group (either family members or friends) were asked to fill out only one questionnaire in order to maximize samples mixture and avoid repetitive responses.

A non-random sampling method was used - "catch-as-catch-can" method (Blair, 1983) in the first stage of sampling, whereby the following accessible person was approached over a continuous period. In order to compensate for the bias that might be imposed by the nonrandom sampling approach conducted on-site, a random sampling was performed using the SPSS software in second stage sampling (Zainudin, 2012). A total of 1,200 questionnaires 
were collected in stage one and after random sampling in stage two in addition to elimination of unusable questionnaires, 868 questionnaires were maintained for data analysis. SEM was conducted to determine the hypothesized relationships in the model. Further, the paths between the constructs were examined for first-time and repeat tourists to determine the differences in terms of behavioral loyalty generation between the groups.

\section{Findings}

\subsection{Demographic Characteristics}

The respondents were divided into two independent groups which are first-time tourists $(n=$ $565)$ and repeat tourists $(n=303)$. First-time tourists were defined as tourists who had never visited the WHS, meanwhile repeat tourists were the tourists who had prior visit experience to the sites. The demographic characteristics and travel information were analyzed using t-test and chi-square test to investigate the existence of any significant patterns between/among the categories. As shown in Table 1, significant difference in gender $\left(\chi^{2}=5.694, p<0.05\right)$, citizenship based on region $\left(\chi^{2}=56.310, p<0.001\right)$ and age $(t=-4.906, p<0.001)$ were found. The percentage of male tourists $(56.1 \%)$ was higher in the repeat tourist category but it was the opposite for first-time tourist category (female $=52.4 \%$ ). The findings showed that there was a higher percentage of first-time tourists from the regions of Americas (17.5\%) and Europe $(62.3 \%)$ than the repeat tourist group (Americas $=8.3 \%$; Europe $=50.3 \%$ ). However, within the Asia and the Pacific group, it was found that the percentage was higher from the repeat tourists $(36.8 \%)$ than first-time tourists $(19.3 \%)$. Geographical distance may be a factor that has encouraged tourists who are from the same region to repeat their visits to the sites. The findings also revealed that first-time tourists $(33.44 \pm 13.264)$ were younger than repeat tourists $(38.49 \pm 14.958)$. There were no significant differences in level of education and personal annual income.

Table 1: Respondent's demographic $(\mathrm{n}=868)$.

\begin{tabular}{|c|c|c|c|}
\hline \multirow[t]{2}{*}{ Characteristics } & \multicolumn{3}{|c|}{ Previous experience } \\
\hline & $\begin{array}{c}\text { First-time tourist } \\
(n=565) \\
n(\%)\end{array}$ & $\begin{array}{c}\text { Repeat tourist } \\
(n=303) \\
n(\%) \\
\end{array}$ & $\begin{array}{c}\text { Result } \\
\chi^{2} \text { value }\end{array}$ \\
\hline Gender & & & $5.694^{*}$ \\
\hline Male & $269(47.6 \%)$ & $170(56.1 \%)$ & \\
\hline Female & $296(52.4 \%)$ & $133(43.9 \%)$ & \\
\hline Missing value & & & \\
\hline Highest level of education & & & 5.741 (n.s.) \\
\hline Primary school & $0(0 \%)$ & $1(0.3 \%)$ & \\
\hline High school & $58(10.3 \%)$ & $38(12.8 \%)$ & \\
\hline Diploma / Certificate & $101(17.9 \%)$ & $58(19.5 \%)$ & \\
\hline Bachelor degree & $226(40.0 \%)$ & $111(37.2 \%)$ & \\
\hline Master degree & $147(26.0 \%)$ & $67(22.5 \%)$ & \\
\hline Doctorate degree & $32(5.7 \%)$ & $22(7.4 \%)$ & \\
\hline Others & $1(0.2 \%)$ & $1(0.3 \%)$ & \\
\hline Personal annual income & & & 9.807 (n.s.) \\
\hline Below US\$25,000 & $226(43.9 \%)$ & $126(44.8 \%)$ & \\
\hline US $\$ 25,000$ - US $\$ 49,999$ & $129(25.0 \%)$ & $66(23.5 \%)$ & \\
\hline US\$50,000 - US\$74,999 & $67(13.0 \%)$ & $44(15.7 \%)$ & \\
\hline US\$75,000 - US\$99,999 & $52(10.1 \%)$ & $14(5.0 \%)$ & \\
\hline US\$100,000 - US\$124,999 & $19(3.7 \%)$ & $18(6.4 \%)$ & \\
\hline US\$125,000 and above & $22(4.3 \%)$ & $13(4.6 \%)$ & \\
\hline
\end{tabular}


Citizenship based on region

Africa

Americas

Asia and the Pacific

Europe

Middle East

Age

$$
\begin{gathered}
4(0.7 \%) \\
99(17.5 \%) \\
109(19.3 \%) \\
352(62.3 \%) \\
1(0.2 \%) \\
x(S D) \\
33.44(13.264)
\end{gathered}
$$

$56.310 * *$

$$
4(1.3 \%)
$$

$111(36.8 \%)$

$152(50.3 \%)$

$10(3.3 \%)$

$x(S D)$
$38.49(14.958)$ $t$-value

$-4.906^{* *}$

\subsection{Tripograhic Characteristics}

As for tourists travel information (Table 2), repeat tourists $(28 \%>4$ nights) had longer duration of stay than first-time tourists $(14.2 \%>4$ nights $) ;\left(\chi^{2}=32.613, p<0.001\right)$. A higher

\begin{tabular}{|c|c|c|c|}
\hline \multirow[t]{2}{*}{ Characteristics } & \multicolumn{3}{|c|}{$\begin{array}{l}\text { Previous experience } \\
\end{array}$} \\
\hline & $\begin{array}{c}\text { First-time tourist } \\
(n=565 \\
n(\%)\end{array}$ & $\begin{array}{c}\text { Repeat tourist } \\
(n=303) \\
n(\%)\end{array}$ & $\begin{array}{c}\text { Result } \\
\chi^{2} \text { value }\end{array}$ \\
\hline Duration of stay & & & $32.613 * *$ \\
\hline $1-2 \operatorname{night}(s)$ & $257(45.6 \%)$ & $129(42.6 \%)$ & \\
\hline 3-4 nights & $227(40.2 \%)$ & $89(29.4 \%)$ & \\
\hline $5-6$ nights & $39(6.9 \%)$ & $28(9.2 \%)$ & \\
\hline 7 nights & $10(1.8 \%)$ & $9(3.0 \%)$ & \\
\hline More than 7 nights & $31(5.5 \%)$ & $48(15.8 \%)$ & \\
\hline Travel partner & & & $25.719 * *$ \\
\hline By yourself & $130(23.0 \%)$ & $80(26.4 \%)$ & \\
\hline Spouse & $160(28.3 \%)$ & $68(22.4 \%)$ & \\
\hline Spouse and child(ren) & $12(2.1 \%)$ & $7(2.3 \%)$ & \\
\hline Friend(s) & $200(35.4 \%)$ & $82(27.1 \%)$ & \\
\hline Family/relative(s) & $50(8.8 \%)$ & $44(14.5 \%)$ & \\
\hline Colleague(s)/business associate & $11(1.9 \%)$ & $18(5.9 \%)$ & \\
\hline Others & $2(0.4 \%)$ & $4(1.3 \%)$ & \\
\hline Accommodation used & & & $14.379^{*}$ \\
\hline Hotel & $203(36.1 \%)$ & $132(43.6 \%)$ & \\
\hline Budget hotel & $59(10.5 \%)$ & $35(11.6 \%)$ & \\
\hline Dormitory/hostel & $116(20.6 \%)$ & $42(13.9 \%)$ & \\
\hline Guesthouse & $168(29.9 \%)$ & $76(25.1 \%)$ & \\
\hline Others & $16(2.8 \%)$ & $18(5.9 \%)$ & \\
\hline Daily food expenditure per person & & & 5.498 (n.s.) \\
\hline Below MYR 50 & $315(55.9 \%)$ & $147(48.7 \%)$ & \\
\hline MYR 50-MYR 99.99 & $180(31.9 \%)$ & $109(36.1 \%)$ & \\
\hline MYR 100-MYR 149.99 & $42(7.4 \%)$ & $26(8.6 \%)$ & \\
\hline MYR 150-MYR 199.99 & $16(2.8 \%)$ & $10(3.3 \%)$ & \\
\hline MYR 200-MYR 249.99 & $6(1.1 \%)$ & $7(2.3 \%)$ & \\
\hline MYR 250 and above & $5(0.9 \%)$ & $3(1.0 \%)$ & \\
\hline
\end{tabular}
percentage of first-time tourists traveled with friends $(35.4 \%)$ than repeat tourists $(27.1 \%) ;\left(\chi^{2}\right.$ $=25.719, p<0.001)$. Repeat tourists $(55.2 \%)$ were found to have better preference for type of accommodation with service (hotel and budget hotel categories) than first-time tourists $(46.6 \%) ;\left(\chi^{2}=14.379, p<0.05\right)$. No significant differences were found in daily food expenditure per person and knowledge about the destination's heritage status between firsttime and repeat tourists.

Table 2: Respondent's tripographic characteristics $(n=868)$. 


\subsection{Reliability and Validity of Measurement Scales}

The reliability and validity of the measurement scales were examined to determine if the instrument was psychometrically rigorous in measuring the constructs. Several measurement items were deleted from the construct of food involvement (i.e. "I do not think or talk much about how the local food tastes"), destination attractiveness (i.e. "availability of currency exchange facilities", "quality of accommodation facilities", "safety and security" and "weather/climate"), and behavioral loyalty (i.e. "I will share my thoughts and / or pictures of my travel experience in my social media account") due to its factor loading did not meet the threshold value of 0.40 (Anderson \& Gerbing, 1988). After elimination of the aforementioned items, all standardized loading estimates were found to be significant $(p<0.001)$ and exceeded the suggested threshold value of 0.40 (Table 3) as suggested by Hair et al., (2014).

The average variance extracted (AVE) for food knowledge, food experience, food image, destination were above the cut-off-point of 0.50 (Hair et al., 2014) except for the construct of involvement that is marginally acceptable with an AVE of 0.48. Meanwhile, the composite reliability (CR) estimates for all constructs exceeded the suggested cut-off point of 0.70 , indicating the respective measurement scales were reliable and thus confirmed the convergent validity of the constructs (Fornell \& Larcker, 1981; Huang et al., 2013).

Table 3: Measurement model convergent validity.

\begin{tabular}{|c|c|c|c|c|}
\hline Construct/Measurement items & $\begin{array}{c}\text { Mean } \\
\text { (SD) }\end{array}$ & $\begin{array}{c}\text { Standardized } \\
\text { Loadings } \\
\text { Estimate }\end{array}$ & $\begin{array}{c}\text { Average } \\
\text { Variance } \\
\text { Extract } \\
\end{array}$ & $\begin{array}{l}\text { Composite } \\
\text { Reliability }\end{array}$ \\
\hline Food involvement (FIN)* & & & 0.48 & 0.86 \\
\hline Curious to know about food & $4.41(0.75)$ & 0.71 & & \\
\hline Eager to involve in unfamiliar food activity & $4.38(0.81)$ & 0.64 & & \\
\hline Always talk/reflect about food & $4.05(0.92)$ & 0.71 & & \\
\hline Want to learn about local food culture & $4.19(0.87)$ & 0.80 & & \\
\hline Want to taste the famous local food & $4.47(0.77)$ & 0.73 & & \\
\hline Eager to ask local residents about local food & $4.10(0.93)$ & 0.66 & & \\
\hline Food choice is important & $4.00(0.94)$ & 0.57 & & \\
\hline Food knowledge (FKN)* & & & 0.54 & 0.85 \\
\hline Read about local food prior to travel & $3.32(1.32)$ & 0.66 & & \\
\hline Aware about local eating customs & $3.21(1.07)$ & 0.71 & & \\
\hline Knowledgeable about local food & $2.85(1.03)$ & 0.79 & & \\
\hline Informed about popular local food & $3.42(1.13)$ & 0.78 & & \\
\hline Informed of the location of popular local food & $3.07(1.13)$ & 0.71 & & \\
\hline Food experience $($ FEX $) *$ & & & 0.57 & 0.84 \\
\hline Enjoyable & $4.20(0.76)$ & 0.80 & & \\
\hline Good service quality & $4.11(0.79)$ & 0.79 & & \\
\hline Learnt about local food culture & $3.97(0.90)$ & 0.68 & & \\
\hline Enhanced travel experience & $4.09(0.91)$ & 0.74 & & \\
\hline Food image (FIMA)* & & & 0.74 & 0.85 \\
\hline Factor 1 - Local food uniqueness & $4.00(0.67)$ & 0.90 & & \\
\hline Factor 2 - Food quality and service & $3.84(0.62)$ & 0.82 & & \\
\hline Destination image (DIMA)** & & & 0.55 & 0.83 \\
\hline
\end{tabular}


Factor 1 - Hospitality and services

Factor 2 - Entertainment

Factor 3 - Accessibility

Factor 4 - Attractions

\section{Overall satisfaction (OSAT)*}

Expectations of destination was met

Destination is value for money

Trip worth time and effort

Overall satisfaction

Behavioral loyalty (BEL)***

Will share experience with family and friends

Will recommend to family and friends

Intention to revisit

$\begin{array}{ll}4.23(0.63) & 0.90 \\ 3.62(0.75) & 0.67 \\ 3.69(0.71) & 0.66 \\ 4.04(0.76) & 0.71\end{array}$

0.59

0.85

$4.08(0.82)$

0.76

$4.14(0.83) \quad 0.72$

$4.29(0.84) \quad 0.76$

$4.40(0.70) \quad 0.83$

0.62

0.83

\footnotetext{
Note $: *$ Scale $=$ Strongly disagree $(1)-$ Strongly agree $(5) ; * *$ Scale $=$ Not at all satisfied $(1)-$ Extremely satisfied $(5) ; * * *$ Scale $=$ Very unlikely (1) - Very likely (5); $S D=$ Standard deviation.

Goodness-of-fit statistics: $\chi^{2}=4246,102, \mathrm{df}=1850, p<0.001, \chi^{2} / \mathrm{df}=2.295, \mathrm{CFI}=0.868, \mathrm{TLI}=0.858, \mathrm{RMSEA}=0.0039$.
}

Subsequently, divergent validity tests were conducted to examine the degree to which the constructs are unrelated. The AVE values were compared to the squared correlations between two constructs (Fornell \& Larcker, 1981). It was found (Table 4) that all the squared correlations between two constructs were less than the AVE of each construct, except for "food image and food experience", "destination image and food image" and "behavioral loyalty and overall satisfaction". The divergent validity for these three pairs were further examined using a chi-square difference test (Bagozzi \& Phillips, 1982). The chi-square tests results revealed that all the pairs were statistically significant (Table 4) with $p$ value less than 0.001. This indicated that food image, food experience, destination image, overall satisfaction and behavioral loyalty captured distinctive attributes that are not redundant in other constructs.

Table 4: Discriminant validity.

\begin{tabular}{|c|c|c|c|c|c|c|c|}
\hline Construct & FIN & FKN & FEX & FIMA & DIMA & OSAT & BEL \\
\hline FIN & 0.48 & & & & & & \\
\hline FKN & 0.14 & 0.54 & & & & & \\
\hline FEX & 0.25 & 0.21 & 0.57 & & & & \\
\hline FIMA & 0.30 & 0.29 & $0.79 * *$ & 0.74 & & & \\
\hline DIMA & 0.14 & 0.12 & 0.53 & $0.67 * *$ & 0.55 & & \\
\hline OSAT & 0.14 & 0.06 & 0.42 & 0.49 & 0.52 & 0.59 & \\
\hline \multirow[t]{3}{*}{ BEL } & 0.14 & 0.10 & 0.30 & 0.40 & 0.34 & $0.62 * *$ & 0.62 \\
\hline & \multicolumn{2}{|c|}{ Combined Model } & \multicolumn{2}{|c|}{ Uncombined Model } & \multirow[t]{2}{*}{$\Delta \chi^{2} / \mathbf{d f}$} & & \multirow[t]{2}{*}{$p$-value } \\
\hline & $\left(\chi^{2}\right)$ & df & $\left(\chi^{2}\right)$ & df & & & \\
\hline FEX-FIMA & 3523.374 & 919 & 3237.771 & 918 & \multirow{3}{*}{\multicolumn{2}{|c|}{$\begin{array}{l}\Delta \chi^{2}(1)=285.603 \\
\Delta \chi^{2}(1)=369.921 \\
\Delta \chi^{2}(1)=304.006\end{array}$}} & 0.000 \\
\hline FIMA-DIMA & 3607.692 & 919 & 3237.771 & 918 & & & 0.000 \\
\hline OSAT-BEL & 3541.777 & 919 & 3237.771 & 918 & & & 0.000 \\
\hline \multicolumn{8}{|c|}{$\begin{array}{l}\text { Note: } \\
\text { - **Value that has exceeded the AVE value for any of the corresponding constructs } \\
\text { - Average Variance Extracted (Diagonal) } \\
\text { - Squared Correlation Coefficient (Off-diagonal) } \\
\text { - FIN = food involvement; FKN = food knowledge; FEX = food experience; FIMA = food image; DIMA = destination image; OSAT = } \\
\text { overall satisfaction; BEL = behavioral loyalty }\end{array}$} \\
\hline
\end{tabular}




\subsection{Mean Difference across First-Time and Repeat Tourists}

Independent $t$-test analyses were conducted to examine the mean differences between firsttime and repeat tourists in all the constructs of the proposed model: food involvement, food knowledge, past food experience, perceived food image, perceived destination image, overall satisfaction and behavioral loyalty. The findings (Table 5) revealed that the means values of food involvement were not significantly different between first-time and repeat tourists $(t=$ $1.780, p>0.05)$. This suggested that both first-time tourists were just as involved as repeat tourists towards the local food. During trips, food is an indispensable factor that adds enjoyment to a tourist. Regardless of first or repeated times of visiting a destination, searching for novel food to experience is a daily repeated activity when one is away from home.

The $t$-test found that food knowledge for repeat tourists $(3.44 \pm 0.86)$ was significantly higher than first-time tourists $(3.03 \pm 0.88)$. This finding suggests that repeat tourists were reported to have more knowledge about the local food due to repeated visitations to the destination. Mean values in food experience $(t=-0.697, p>0.05)$, perceived food image $(t=-$ $0.438, p>0.05)$, perceived destination image $(t=1.387, p>0.05)$, overall satisfaction $(t=$ $0.522, p>0.05)$ were not significantly different across the two groups. The results led to a conclusion that first-time and repeat tourists had similar perceptions in terms of their food experience and the perceived image of the destination and local food. In addition, both groups were equally satisfied with the destination that they visited. Repeat tourist $(4.35 \pm 0.67)$ showed a significantly higher behavioral loyalty than that of first-time tourists $(4.13 \pm 0.79)$. This indicated that repeat tourists were more willing to revisit the destination again in addition to recommending or spreading positive word-of-mouth about the destination.

Table 5: Mean difference between first-time and repeat tourists.

\begin{tabular}{|c|c|c|c|c|c|}
\hline \multirow[t]{2}{*}{ Variables } & \multicolumn{2}{|c|}{$\begin{array}{l}\text { First-time tourists } \\
\quad(n=565)\end{array}$} & \multicolumn{2}{|c|}{$\begin{array}{c}\text { Repeat tourists } \\
\quad(n=303)\end{array}$} & \multirow[b]{2}{*}{$t$-value } \\
\hline & Mean & SD & Mean & SD & \\
\hline Food involvement & 4.26 & 0.62 & 4.18 & 0.65 & 1.780 (n.s.) \\
\hline Food knowledge & 3.03 & 0.88 & 3.44 & 0.86 & $-6.667 * *$ \\
\hline Food experience & 4.08 & 0.71 & 4.11 & 0.65 & -0.697 (n.s.) \\
\hline Perceived food image & 3.92 & 0.59 & 3.94 & 0.57 & -0.438 (n.s.) \\
\hline Perceived destination image & 3.98 & 0.50 & 3.93 & 0.53 & 1.387 (n.s.) \\
\hline Overall satisfaction & 4.24 & 0.67 & 4.21 & 0.65 & 0.522 (n.s.) \\
\hline Behavioral loyalty & 4.13 & 0.79 & 4.35 & 0.67 & $-4.217 * *$ \\
\hline
\end{tabular}

\subsection{Moderating Effect of Past Visit Experience}

The moderating effect of tourists past visit experience on the relationships between food involvement, food knowledge, food experience, food image, destination image, overall satisfaction and behavioral loyalty were examined. The results obtained from the multiplegroup analysis revealed that the chi-square difference between constrained model $\left(\chi^{2}=\right.$ 4482.26, $\mathrm{df}=1961)$ and unconstrained model $\left(\chi^{2}=4248.827\right.$, $\left.\mathrm{df}=1852\right)$ was statistically significant $\left(\Delta \chi^{2}(109)=233.433, p<0.001\right)$. Therefore, it was anticipated that there were differences in the structural path across first-time and repeat tourists in the proposed tourists' behavioral loyalty model. Each path in the structural model was examined and the results are discussed in the following section.

\subsection{Structural Models For First-Time and Repeat Tourists}

Given that the chi-square test results showed that there were some form of moderation effect existed in the structural model, all the paths between the constructs were examined for firsttime and repeat tourists. Table 6 and Figures 2 and 3 present the findings of the structural models for first-time and repeat tourists. For first-time tourists (Figure 2) the components 
forming food preference have positive and significant influence on food image [food involvement $\rightarrow$ food image $\left(\beta_{\mathrm{FIN}_{\rightarrow} \text { FIMA }}=0.093, t_{\mathrm{FIN}} \rightarrow \mathrm{FIMA}=2.179, p<0.05\right)$; food knowledge $\rightarrow$ food image $\left(\beta_{\mathrm{FKN}_{\rightarrow} \mathrm{FIMA}}=0.210, t_{\mathrm{FKN}_{\rightarrow} \mathrm{FIMA}}=4.913, p<0.001\right)$; food experience $\rightarrow$ food image $\left.\left(\beta_{\mathrm{FEX}} \rightarrow \mathrm{FIMA}=0.726, t_{\mathrm{FEX}} \rightarrow{ }_{\mathrm{FIMA}}=13.277, p<0.001\right)\right]$, but not on destination image. Thus, $\mathrm{H} 1 \mathrm{a}, \mathrm{H} 2 \mathrm{a}$ and $\mathrm{H} 3 \mathrm{a}$ were supported, but $\mathrm{H} 1 \mathrm{~b}, \mathrm{H} 2 \mathrm{~b}$ and $\mathrm{H} 3 \mathrm{~b}$ were unsupported.

Table 6: Comparison of parameter estimates between first-time and repeat tourists.

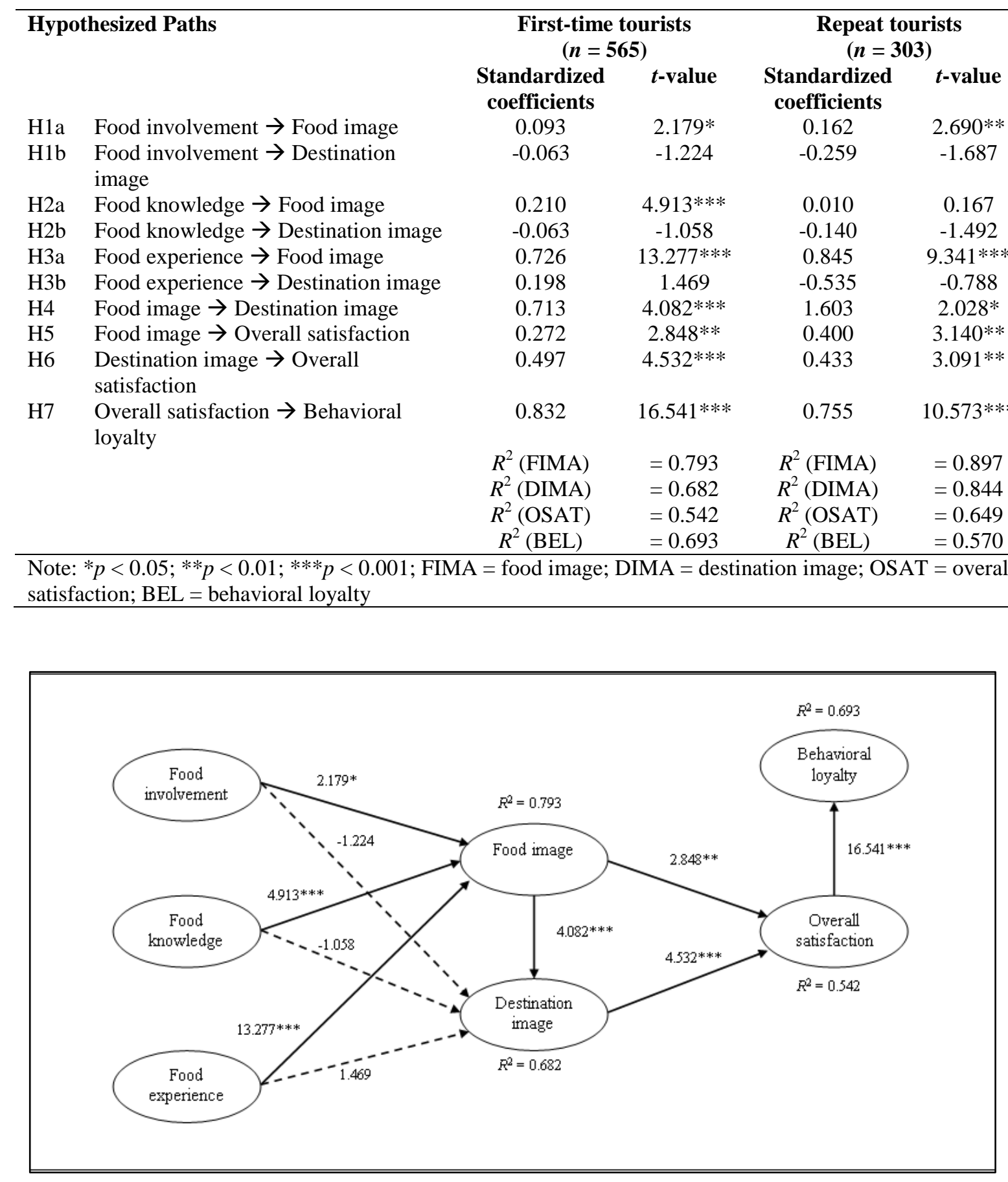

Figure 2: Structural model for first-time tourists. 


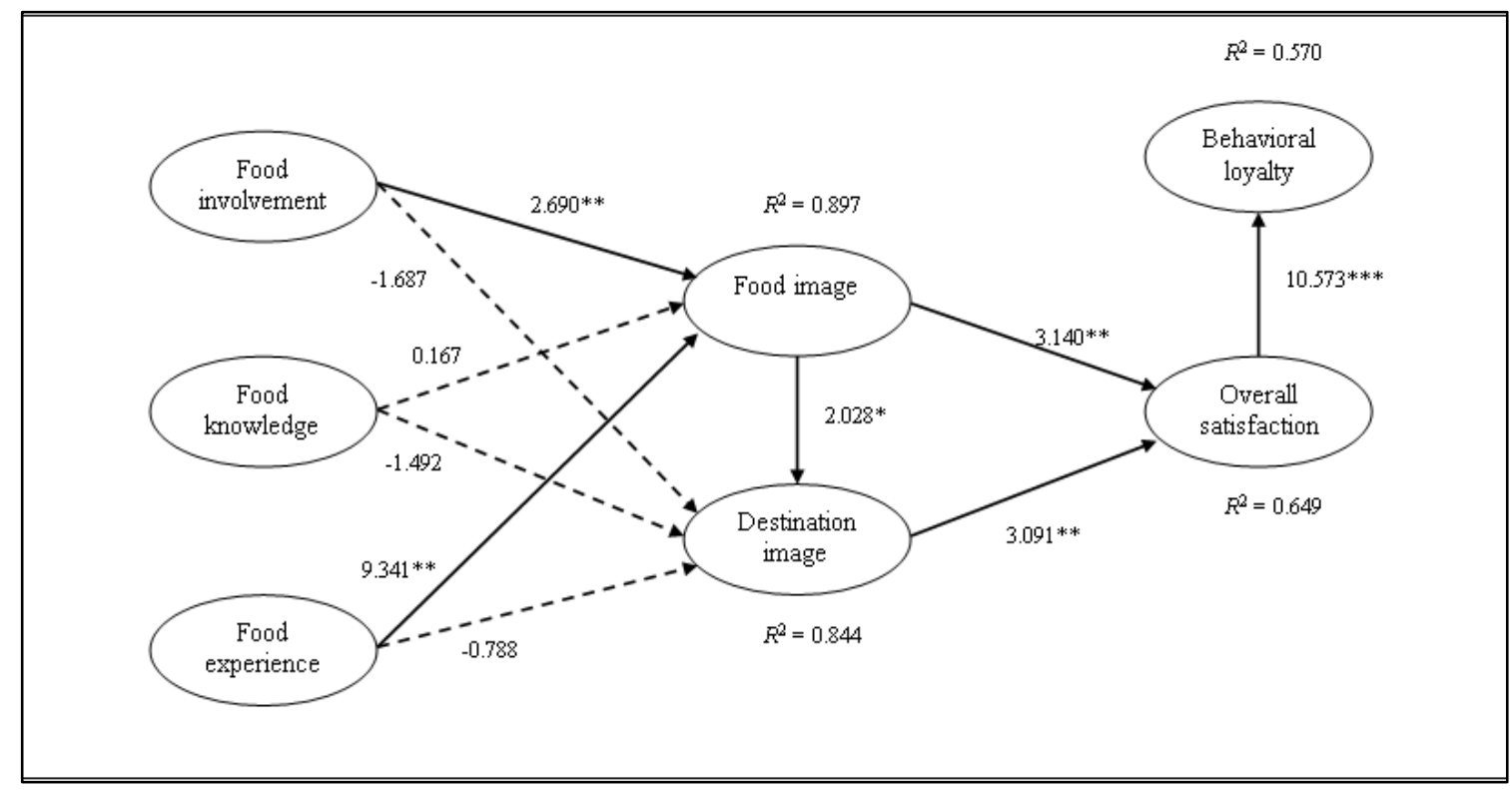

Figure 3: Structural model for repeat tourists.

Meanwhile, in the repeat tourists' model (Figure 3), the effect of food involvement $\left(\beta_{\mathrm{FIN}_{\rightarrow} \mathrm{FIMA}}=0.162, t_{\mathrm{FIN}} \rightarrow \mathrm{FIMA}=2.690, p<0.01\right)$ and food experience $\left(\beta_{\mathrm{FEX}_{\rightarrow}{ }_{\mathrm{FIMA}}}=0.845\right.$, $\left.t_{\mathrm{FEX}} \rightarrow \mathrm{FIMA}=9.341, p<0.001\right)$ were found to be statistically significant on food image and thus supporting H1a and H3a. Food knowledge had no significant effect on food image $\left(\beta_{\text {FEX } \rightarrow \text { FIMA }}\right.$ $\left.=0.010, t_{\mathrm{FEX}} \rightarrow \mathrm{FIMA}=0.167, p>0.05\right)$ in the repeat tourists' model, thus $\mathrm{H} 2 \mathrm{a}$ was rejected. This result suggested that information sources of local food was not a crucial factor affecting repeat tourists' perceived food image. All the components forming food preference (i.e. food involvement, food knowledge and food experience) was found to be not associated with destination image in the repeat tourist's model. Thus, similar to the first-time tourists' model, $\mathrm{H} 1 \mathrm{~b}, \mathrm{H} 2 \mathrm{~b}$ and $\mathrm{H} 3 \mathrm{~b}$ were rejected.

Perceived food image was significantly associated with destination image for first-time $\left(\beta_{\mathrm{FIMA}_{\rightarrow} \mathrm{DIMA}}=0.713, t_{\mathrm{FIMA}_{\rightarrow} \mathrm{DIMA}}=4.082, p<0.001\right)$ and repeat tourists $\left(\beta_{\mathrm{FIMA}_{\rightarrow} \mathrm{DIMA}}=1.603\right.$, $\left.t_{\mathrm{FIMA}_{\rightarrow} \mathrm{DIMA}}=2.028, p<0.05\right)$ as well as with overall satisfaction for first-time $\left(\beta_{\mathrm{FIMA}} \rightarrow \mathrm{OSAT}=\right.$ $\left.0.272, t_{\text {FIMA }_{\rightarrow} \mathrm{OSAT}}=2.848, p<0.05\right)$ and repeat tourists $\left(\beta_{\mathrm{FIMA}_{\rightarrow} \mathrm{OSAT}}=0.400, t_{\mathrm{FIMA}_{\rightarrow} \mathrm{OSAT}}=\right.$ $3.140, p<0.05)$, supporting $\mathrm{H} 4$ and H5. Destination image was a positive and significant predictor of overall satisfaction for first-time $\left(\beta_{\mathrm{DIMA}_{\rightarrow} \mathrm{OSAT}}=0.497, t_{\mathrm{DIMA}_{\rightarrow} \mathrm{OSAT}}=4.532, p<\right.$ $0.05)$ and repeat tourists $\left(\beta_{\mathrm{DIMA}_{\rightarrow} \mathrm{OSAT}}=0.433, t_{\mathrm{DIMA}_{\rightarrow} \mathrm{OSAT}}=3.091, p<0.05\right)$, supporting H6. As expected, overall satisfaction was a positive function of behavioral loyalty for first-time $\left(\beta_{\mathrm{OSAT}_{\rightarrow} \mathrm{BEL}}=0.832, t_{\mathrm{OSAT}_{\rightarrow} \mathrm{BEL}}=16.541, p<0.05\right)$ and repeat tourists $\left(\beta_{\mathrm{OSAT}_{\rightarrow} \mathrm{BEL}}=0.755\right.$, $\left.t_{\mathrm{OSAT}} \rightarrow \mathrm{BEL}=10.573, p<0.05\right)$, supporting $\mathrm{H} 7$.

\section{Conclusion, Implications and Limitations}

This study's purpose was twofold. First, the study investigates the mean differences in food involvement, food knowledge, food experience, food image, destination image, overall satisfaction and behavioral loyalty between first-time and repeat tourists in Malaysia's WHS (i.e. Melaka and George Town). Second, the study explores if past visit experience influences the magnitude of the structural relationships of the proposed tourist behavior models (firsttime versus repeat).

The $t$-test results showed that repeat tourists had significantly higher food knowledge and behavioral loyalty than first-time tourists. These results were as expected as the repeat 
tourists have had higher frequency of visits to the destinations as compared to the first-time tourists. Thus, they would have gained more food information through higher sampling frequencies which consequently contributed to a higher behavioral loyalty. However, the results showed that there were no significant differences between the groups in food involvement, food experiences, food image, destination image and overall satisfaction. This suggested that the first-time and repeat tourists were equal in the characteristics measured.

The potential variances in the systematic relationships between the constructs across the first-time and repeat tourists were examined using multiple-group analysis. It was found that past visit experience has significantly influenced the structural relationships between the constructs, suggesting differences exists between the first-time and repeat tourist's groups, specifically in the path between food knowledge and perceived food image (Figure 1 and 2). Food involvement, food knowledge and food experience were found to have significant effects of food image among the first-time tourists. Meanwhile, in the repeat tourist's model, only food involvement and food experience had significant influence on food image. This implied that both first-time and repeat tourists were equally involved in food exploration as well as having memorable food experience in the destinations. However, the structural relationship between food knowledge and food image among the repeat tourists was insignificant. This result is inconsistent with past literature (Guan \& Jones, 2015; Huang et al., 2013) which suggest that tourists with higher familiarity of a destination's local food will naturally have favorable perceived images.

A plausible explanation for this inconsistency might be due to the effect of information backlog. According to Jeong and Holland (2012), repeated exposure to destination's information would in fact reach a saturation level. The information gained through repeated visits become saturated and has little or no effect on image generation in tourists. Results obtained in this study may indicate that there might be some dysfunctional concerns in terms of the local food information dissemination among the repeat tourists. Repeat tourists might repeat the same old trail of food exploration and hence creating a monotonous effect on perceived food image; whereas, the first-time tourists were absorbing their new encounters like a sponge and hence contributed to a positive perceived food image.

Drawing from the results, it is extremely important for destination marketers to take note that first-time and repeat tourists are two categories of tourists with different levels of food expectations and needs for local food information. In order to retain the repeat tourists for more future visits, destination marketers should progressively provide innovative and up-todate local food information guide via multiple media channels to facilitate in creating new material surprises to repeat tourists. For example, capitalizing on social media such as Facebook, Instagram, and Tweeter (which incur minimal cost), destination marketers may produce groundbreaking write-ups on local food on a continual basis. Stories may create images in the mind of tourists, instead of mere local food introductory brochure or guide book that is literally monotonous. In addition, reading food stories might also aid in reconnecting repeat tourists' to a destination local food experiences, hence contribute in generating positive food images. At the same time, this strategy would also act to convert first-time tourists into repeat tourists.

The limitation of this study is that the research results could barely be expected to represent all international tourists in Malaysia but only a certain portion of the international tourists who were surveyed in the selected setting of survey duration, considering that the nature of the survey was cross-sectional and not longitudinal. As such, future research may consider conducting a longitudinal survey approach, in which data can be collected on selected days of each month of a year. In such a way, the causal inferences, as hypothesized in the proposed model, can be measured more precisely but with a downside of higher cost to be incurred. 
In addition, the research data was collected in the month of January and February 2015 in George Town and Melaka respectively. Therefore, the findings were limited to international tourists who visited the WHS at the beginning of the year. Malaysia is a tropical country that has no seasonality restrictions; however, the selected WHS destinations are extraordinarily more festive around July and August due to a lineup of yearly celebrations that commemorate the cities' world heritage status inscription by UNESCO. International tourists who visit the WHS cities during this period may have different perceptions and feelings toward the WHS. Therefore, future studies is suggested to be conducted during the month-long celebrations in the WHS and consequently, a comparison between the timing of survey can be made to determine the dissimilarities and correspondences in the tourists' perceptions and behavior.

\section{References}

Almeida, A., \& Garrod, B. (2017). Experiences with local food in a mature tourist destination: The importance of consumers' motivations. Journal of Gastronomy and Tourism, 2(3), 173-187.

Anderson, J. C., \& Gerbing, D. W. (1988). Structural equation modeling in practice: A review and recommended two-step approach. Psychological Bulletin, 103, 411-423.

Andriotis, K., Agiomirgianakis, G., \& Mihiotis, A. (2008). Measuring tourist satisfaction: A factor-cluster segmentation approach. Journal of Vacation Marketing, 14, 221-235.

Bagozzi , R. P., \& Phillips, L. W. (1982). Representing and testing organizational theories: A holistic construal. Administrative Science Quarterly, 27(3), 459-489.

Barton, R. (2014). Where are the foodies going in 2014? Retrieved from Lonely Planet web site: http://www.independent.co.uk/travel/news-andadvice/ where-are-the-foodiesgoing-in-2014-9094744.html

Belk, R. W. (1981). Effects of gift-giving involvement on gift selection strategies. In A. Mitchell, \& A. Arbor (Eds.), Advances in consumer research (Vol. 9, pp. 408-412). MI: Association for Consumer Research.

Blair, E. (1983). Sampling issues in trade area maps drawn from shopper surveys. Journal of Marketing, 47(Winter), 98-106.

Bryan, H. (1977). Leisure value systems and recreational specialization: The case of trout fishermen. Journal of Leisure Research, 9(3), 174-187.

Buhalis, D. (2001). Tourism in Greece: Strategic analysis and challenges. Current Issues in Tourism, 4(3), 440-480.

Campon, A. M., Alves, H., \& Hernandez, J. M. (2013). Loyalty measurement in tourism: A theoretical reflection. In Á. Matias, P. Nijkamp, \& M. Sarmento (Eds.), Quantitative methods in tourism economics (pp. 13-40). Berlin Heidelberg: Physica-Verlag Heidelberg.

Charters, S., \& Ali-Knight, J. (2002). Who is the wine tourists? Tourism Management, 23(3), 311-319.

Chen, C.-F., \& Tsai, D.-C. (2007). How destination image and evaluation factors affect behavioral intentions? Tourism Management, 28(4), 1115-1122.

Chen, Q., \& Huang, R. (2016). Understanding the importance of food tourism in Chongqing, China. Journal of Vacation Marketing, 22(1), 42-54.

Civitello, L. (2008). Cuisine and culture: A history of food and people. New Jersey: John Wiley \& Sons.

Cracolici, M. F., \& Nijkamp, P. (2008). The attractiveness and competitiveness of tourist destinations: A study of southern Italian regions. Tourism Management, 30(3), 336344. 
Dick, A. S., \& Basu, K. (1994). Customer loyalty: Toward an integrated conceptual framework. Journal of the Academy of Marketing Science, 22(2), 99-113.

Engel, F., \& Blackwell, R. D. (1982). Consumer behavior. Minnesota: Dryden Press.

Eusébio, C., \& Vieira, A. L. (2013). Destination attributes' evaluation, satisfaction and behavioural intentions: A structural modelling approach. Journal of Tourism Research, 15(1), 66-80.

Fields, K. (2002). Demand for the gastronomy tourism product: Motivational factors. In A. Hjalager, \& G. Richards (Eds.), Tourism and gastronomy (pp. 37-50). London: Routledge.

Fornell, C., \& Larcker, D. F. (1981). Evaluating structural equations models with with unobservable variables and measurement error. Journal of Marketing Research, 18(February), 39-50.

Gallarza, M. G. \& Saura, I. G. (2006). Value dimensions, perceived value, satisfaction and loyalty: An investigation of university students' travel behavior. Tourism Management, 27(3), 437-452.

Gearing, C. E., Swart, W. W., \& Var, T. (1974). Establishing a measure of touristic attractiveness. Journal of Travel Research, 12(4), 1-8.

Guan, J. J. (2012). Review of gourmet abroad and tourism studies: Talking about the extensive phenomenon of the concept of gourmet travel. Tourism Tribune, 27(10), 8592.

Guan, J., \& Jones, D. L. (2015). The contribution of local cuisine to destination attractiveness: an analysis involving Chinese tourists' heterogeneous preferences. Asia Pacific Journal of Tourism Research, 20(4), 416-434.

Hair, J.-F. J., Black, W. C., Babin, B. J., \& Anderson, R. E. (2014). Multivariate data analysis (Seventh ed.). USA: Pearson Education Limited.

Han, H., Nguyen, H. N., Song, H., Chua, B.-L., Lee, S., \& Kim, W. (2018). Drivers of brand loyalty in the chain coffee shop industry. International Journal of Hospitality Management, 72(June), 86-97.

Hendijani, R. B., \& Boo, H. C. (2014). Food hunting - A search of the past and dream of the future. 5th Asia Euro Conference 2014. 144, pp. 218-222. Procedia - Social and Behavioral Sciences.

Henkel, R., Henkel, P., Agrusa, W., Agrusa, J., \& Tanner, J. (2006). Thailand as a tourist destination: Perceptions of international visitors and Thai residents. Asia Pacific Journal of Tourism Research, 11(3), 269-287.

Hjalager, A.-M., \& Corigliano, M. A. (2000). Food for tourists - Determinants of an image. International Journal of Tourism Research, 2(4), 281-293.

Horng, J. S., \& Tsai, C. T. (2012). Constructing indicators of culinary tourism strategy: An application of resource-based theory. Journal of Travel \& Tourism Marketing, 29(8), 796-816.

Hu, Y. Z., \& Ritchie, J.-R. B. (1993). Measuring destination attractiveness: A contextual approach. Journal of Travel Research, 35(4), 42-49.

Huang, C.-C., Wang, Y.-M., Wu, T.-W., \& Wang, P.-A. (2013). An empirical analysis of the antecedents and performance consequences of using the moddle platform. International Journal of Information and Education Technology, 3(20), 217-221.

Hui, T. K., Wan, D., \& Ho, A. (2007). Tourists' satisfaction, recommendation and revisiting Singapore. Tourism Management, 28(4), 965-975.

Hussin, H. (2018). Gastronomy, Tourism, and the Soft Power of Malaysia. SAGE Open, Online first, 1-11.

Jacoby, J., \& Kyner, D. B. (1973). Brand loyalty vs. repeat purchasing behavior. Journal of Marketing Research, 10(1), 1-9. 
Jeong, C., \& Holland, S. (2012). Destination image saturation. Journal of Travel \& Tourism Marketing, 29(6), 501-519.

Khoo, S. L., \& Badarulzaman, N. (2014a). Branding George Town world heritage site as city of gastronomy: Prospects of creative cities strategy in Penang. International Journal of Culture, Tourism and Hospitality Research, 8(3), 322-332.

Khoo, S. L., \& Badarulzaman, N. (2014b). Factors determining George Town as a city of gastronomy. Tourism Planning \& Development, 11(4), 371-386.

Khor, N.-J. K. (2006). Nonya flavours: A complete guide to Penang Straits Chinese cuisine. Kuala Lumpur: Star Publications.

Kim, Y. H., Kim, M. C., \& Goh, B. K. (2011). An examination of food tourists' behavior: Using the modified theory of reasoned action. Tourism Management, 32(5), 11591165.

Kivela, J., \& Crotts, J. C. (2006). Tourism and gastronomy: Gastronomy's influence on how tourists experience a destination. Journal of Hospitality and Tourism Research, 30(3), 354-377.

Kozak, M., \& Rimmington, M. (1999). Measuring tourist destination competitiveness: Conceptual considerations and empirical findings. International Journal of Hospitality Management, 18(3), 273-283.

Leong, Q.-L., Ab. Karim, S., Chua, B.-L., \& Tengpongsathon, K. (2017). Middle East Tourists' Behavior towards Malaysian Gastronomy and Dining Experience in Malaysia. International Journal of Tourism and Hospitality Management in the Digital Age, 1(2), 64-79.

Mak, A. H.-N., Lumbers, M., Eves, A., \& Chang, R. C.-Y. (2012). Factors influencing tourist food consumption. International Journal of Hospitality Management, 31(3), 928-936.

Mayo, E. J., \& Jarvis, L. P. (1981). Psychology of leisure travel. Boston: C.B.I. Publishing Co.

McIntyre, N., \& Pigram, J. J. (1992). Recreation specialization reexamined: The case of vehicle-based campers. Leisure Sciences, 14(1), 3-15.

McKercher, B., Ho, S.-Y. P., Du Cros, H., \& Chow, S.-M. B. (2002). Activities-based segmentation of the cultural tourism market. Journal of Travel \& Tourism Marketing, 12(1), 23-46.

Mitchell, A. A. (1979). Involvement: A potentially important mediator of consumer behaviour. In W. L. Wilkie, \& A. Arbor (Eds.), Advances in Consumer Research (Vol. 6, pp. 191-196). MI: Association for Consumer Research.

Mitchell, R., \& Hall, M. (2003). Consuming tourists: Food tourism consumer behavior. In C. M. Hall, L. Sharples, R. Mitchell, N. Macionis, \& B. Cambourne (Eds.), Food tourism around the world: Development management and markets (pp. 60-80). Oxford: Butterworth-Heinemann.

Mumuni, A. G., \& Mansour, M. (2014). Activity-based segmentation of the outbound leisure tourism market of Saudi Arabia. Journal of Vacation Marketing, 20(3), 239-252.

Okumus, B., Okumus, F., \& McKercher, B. (2007). Incorporating local and international cuisines in the marketing of tourism destinations: The cases of Hong Kong and Turkey. Tourism Management, 28(1), 253-261.

Oliver, R. L. (2010). Satisfaction: A behavioural perspective on the consumer. New York: Routledge.

Omar, S. R., \& Omar, S. N. (2018). Malaysian heritage food (MHF): A review on its unique food culture, tradition and present lifestyle. International Journal of Heritage, Art and Multimedia, 1(3), 1-15.

Petrick, J. F. (2004). Are loyal visitors desired visitors? Tourism Management, 25(4), 463470. 
Quan, S., \& Wang, N. (2004). Towards a structural model of the tourist experience: An illustration from food experience in tourism. Tourism Management, 25(3), 297-305.

Rao, A. R., \& Monroe, K. B. (1988). The moderating effect of prior knowledge on cue utilization in product evaluations. Journal of Consumer Research, 15, 253-264.

Reibstein, D. J., Loveloca, C. H., \& Dobson, R. (1980). The direction of causality between perceptions, affect and behavior: An application to travel behavior. Journal of Consumer Research, 6, 370-376.

Reitsamer, B. F., \& Brunner-Sperdin, A. (2015). Tourist destination perception and wellbeing: What makes a destination attractive? Journal of Vacation Marketing, 1-18.

Ritchie, J.-R. B., \& Crouch, G. I. (2003). The competitive destination: A sustainable tourism perspective. Wallingford, UK: CABI Publishing.

Rodriguez Molina, M. A., Frias-Jamilena, D.-M., \& Castaneda-Garcia, J. A. (2013). The moderating role of past experience in the formation of a tourist destination's image and in tourists' behavioral intentions. Current Issues in Tourism, 16(2), 107-127.

Rust, R. T., \& Oliver, R. L. (2000). Should we delight the customer? Journal of the Academy of Marketing Science, 28(1), 86-94.

San Martin, H., Collado, J., \& del Bosque, I. R. (2013). An exploration of the effects of past experience and tourist involvement on destination loyalty formation. Current Issues in Tourism, 16(4), 327-342.

Sanchez-Canizares, S. M., \& Lopez-Guzman, T. (2012). Gastronomy as a tourism resource: Profile of the culinary tourist. Current Issues in Tourism, 15(3), 229-245.

Schiffman, L., \& Kanuk, L. (2009). Consumer behavior. New Jersey: Prentice Hall.

Stanley, J., \& Stanley, L. (2015). Food Tourism. Oxfordshire: CABI.

Swarbrooke, J., \& Horner, S. (2007). Consumer behaviour in tourism (2nd ed.). Oxford: Butterworth and Heinemann.

Tan, P. L., Md. Noor, S., Mustafa, H., \& Kiumarsi, S. (2019). Mindfulness: Exploring visitor and communication factors at Penang heritage sites. SEARCH Journal of Media and Communication Research, 11(1), 133-148.

Tourism Malaysia (2016, March 18). Malaysia Tourism Statistics in Brief. Retrieved from Tourism Malaysia Web site: http://www.tourism.gov.my/statistics

Trauer, B. (2006). Conceptualizing special interest tourism - Frameworks for analysis. Tourism Management, 27(2), 183-200.

UNESCO, United Nations Educational, Scientific and Cultural Organization (2008). Melaka and George Town (Malaysia). Retrieved December 18, 2014, from UNESCO web site: http://whc.unesco.org/archive/advisory_body_evaluation/1223bis.pdf, pp. 77-78

UNWTO, United Nation World Tourism Organization (2017). Second Global Report on Gastronomy Tourism. Madrid, Spain: World Tourism Organization (UNWTO).

Yi, Y. (1990). A critical review of consumer satisfaction. In V. Zeithaml (Ed.), Review of marketing (pp. 68-123). Chicago, IL: American Marketing Association.

Yousefi, M., \& Marzuki, A. (2015). An analysis of push and pull motivational factors of international tourists to Penang, Malaysia. International Journal of Hospitality \& Tourism Administration, 16(1), 40-56.

Zainudin, A. (2012). Research methodology and data analysis (5th ed.). Shah Alam: University Technology MARA Publication Centre (UiTM Press).

Zakaria, H., \& Aziz, A. (2018). Kuala Selangor perceived attractiveness as a domestic tourism destination. Journal of Tourism, Hospitality \& Culinary Arts, 10(2), 63-80.

Zhang, H. L., Yang, Y., Zheng, C. H., \& Zhang, J. (2016). Too dark to revisit? The role of past experiences and intrapersonal constraints. Tourism Management, 54(June), 452464. 


\section{Author Biography}

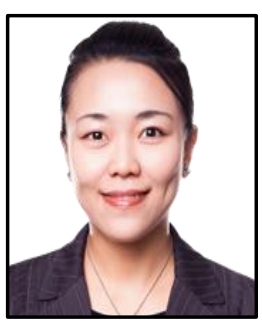

Quee-Ling Leong is a lecturer in hospitality and tourism management in the Faculty of Hospitality and Tourism Management at UCSI University, Kuala Lumpur, Malaysia. She holds a Ph.D. from Universiti Putra Malaysia specializing in gastronomy tourism and tourist behavior. Prior to her Ph.D. study, she has served in the Malaysia Convention and Exhibition Bureau (MyCEB) as Business Development Executive. Her major research interests are in the areas of sustainability of Malaysian heritage gastronomy, food behavior and destination marketing.

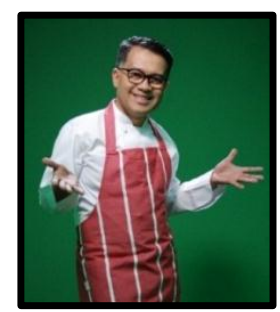

Shahrim Karim is an Associate Professor at the Department of Food Service Management, Faculty of Food Science and Technology, Universiti Putra Malaysia. He received an Associate Degree in Chef Training from Universiti Teknologi MARA and his first degree was in B.Sc. Hotel and Restaurant Management, New York University. Next, he pursued MBA at Universiti Tekhnologi MARA, Shah Alam, Malaysia. In 2006, he was awarded with Doctor of Philosophy Degree in Human Environmental Sciences with a specialization in Hospitality Tourism Administration in Oklahoma State University. His research interest includes foodservice management, food tourism, food culture, and heritage food. He conducts both the quantitative and qualitative research. 